\title{
Adolescent Anemia: Risk Factors
}

\author{
Aulakh R \\ ${ }^{1}$ Dr. Roosy Aulakh, Associate Professor, Department of Pediatrics, Goverment Medical College \& Hospital, Sector 32, \\ Chandigarh, India.
}

Address for Correspondence: Dr. Roosy Aulakh, Associate Professor, Department of Pediatrics, Sector 32, Chandigarh,drroosy@gmail.com

\begin{abstract}
Anemia is common nutritional problem in developing countries like India. It affects both obese as well as undernourished children. Adolescent population especially girls are at risk for development of severe Anemia.
\end{abstract}

Keywords: Anemia, Adolescent, public health problem

\section{Introduction}

Anemia among adolescents is a major public health problem globally. Anemia is well known to retard psychomotor development and impair cognitive performance. Iron deficiency anemia constitutes the major anemia during adolescence. However, megaloblastic anemia and dimorphic anemia have also been reported among adolescents. A thorough evaluation of risk factors associated with adolescent anemia is a pre-requisite for planning preventative and therapeutic measures.

Adolescence (10 to 19 years as per WHO definition) is a vulnerable period for development of anemia due to rapid growth spurt and changing behavioral, dietary and lifestyle habits amongst adolescents. Female adolescents suffer the worst due to still prevalent gender bias in provision of good nutrition and education opportunities to females in resource limited sections of society.

The onset of menarche contributes further in increasing risk of development of anemia among female adolescents. Various previous studies have highlighted high prevalence rates of anemia among adolescents in India. A cross-sectional survey conducted in an urban area of Nagpur reported prevalence of anemia to be $35.1 \%$ among female adolescents [1].

Toteja GS et al found 90.1\% prevalence of anemia among adolescent girls from 16 districts of India, with $7.1 \%$ having severe anemia [2]. The present prospective study by Kavthekar S et al carried out among 1200 rural school going adolescent girls in Maharashtra reported overall prevalence of anemia to be $54.2 \%$ [3].

A significant association of anemia with socioeconomic and literacy status of parents is well established. Increased households incomes have been observed to be associated with higher meat and dairy products consumption thereby reducing chances of development of nutritional anemia.

Better educational status of parents could have multifactorial effects: better choice of healthy food items, higher awareness amongst caregivers about need for preventing and treating anemia in adolescents, hygienic food habits with reduced rates of parasitic infections and overall improved socio-economic status of the family.

Dietary deficiencies and intestinal parasitic infections are other major contributors towards increasing prevalence rates of anemia among adolescents. Iron requirement increases two to three folds from preadolescent to adolescent stage. These, if unmet, can lead to development of iron deficiency anemia. In adolescents, body image issues, examination anxiety and irregular eating habits with skipping of meals are the major causes for the lower intake of animal source foods leading to anemia.

Higher consumption of junk food deficient in essential micronutrients increases the rates of anemia prevalence amongst adolescents. In the study by Kavthekar S et al 
underweight adolescent girls with low Body Mass Index (BMI) were significantly anemic (74.2\%). Consumption of unhygienic food from food vendors infected with faeco-orally transmitted parasites can result in increased prevalence of parasitic infections among adolescents resulting in development of anemia.

An association between earlier menarche age and risk of anemia has also been observed in previous studies documenting much higher prevalence rates of anemia among post-menarcheal girls than pre-menarchael girls. This could be because of hormonal changes which occur at the time of onset of menarche and blood loss during menstruation.

A meta-analysis of seven studies involving 5183 participants concluded that Vitamin D deficiency is also associated with increased risk of anemia, especially iron deficiency anemia, in healthy female children and adolescents [4].

Anemia among adolescents and adults is a universal nutritional problem. Adolescents, being more receptive to new ideas and health based interventions, are best targets to address this issue of anemia. To reduce anemia among pregnant women, attention has presently shifted globally towards reducing prevalence of anemia amongst adolescent females rather than providing iron supplements to pregnant women. This ensures better iron stores at time of conception in females. Moreover, outreach to adolescents through school based programs is much easier.

Interventions to prevent and/or correct anemia in adolescents, if based on thorough assessment of risk factors leading to development of anemia amongst adolescents, shall prove more beneficial and costeffective.
Kavthekar S et al have published an article in this issue related with risk factors for anemia quoted those underweight adolescent girls, girls from Class V and IV socioeconomic status and girls who attained menarche at earlier age were at risk of developing anemia. The government's anemia prevention and control programme should focus on rural adolescent girls [5].

Funding: Nil, Conflict of interest: Nil

Permission from IRB: Yes

\section{References}

1. Chaudhary SM, Dhage VR. A Study of Anemia Among Adolescent Females in the Urban Area of Nagpur. Indian Journal of Community Medicine: Official Publication of Indian Association of Preventive \& Social Medicine. 2008;33(4):243-245.

2. Toteja GS, Singh P, Dhillon BS, Saxena BN, Ahmed FU, Singh RP, et al. Prevalence of anaemia among pregnant women and adolescent girls in 16 districts of India. Food Nutr Bull. 2006;27:311-5.

3. Kavthekar S, Kulkarni D, Kurane A,Chougule A. Association of BMI, socioeconomic status and menarche age with anemia in rural school going adolescent girls. Int J Pediatr Res.2016;3(7):490-496

4. Liu T, Zhong S, Liu L, Liu S, Li X, Zhou T, Zhang J. Vitamin D deficiency and the risk of anemia: a metaanalysis of observational studies. Ren Fail. 2015 Jul;37(6):929-34.

5. Kavthekar S, Kulkarni D, Kurane A,Chougule A. Association of BMI, socioeconomic status and menarche age with anemia in rural school going adolescent girls. Int J Pediatr Res.2016;3(7):490496.doi:10.17511/ijpr.2016.7.04.

\section{How to cite this article?}

Aulakh R. Adolescent Anemia: Risk Factors. Int J Pediatr Res.2016;3(7):477-478.doi:10.17511/ijpr.2016.i07.01. 